\title{
Elucidation of Latent Risk of Navigation Using an Actual Ship Behavior Analysis
}

\author{
Xinjia Gao ${ }^{1}$, Hidenari Makino ${ }^{2}$ and Masao Furusho ${ }^{1}$ \\ 1. Graduate School of Maritime Sciences, Kobe University, Hyogo 658-0022, Japan \\ 2. Naval Architecture \& Ocean Engineering, Osaka University, Osaka 565-0871, Japan
}

\begin{abstract}
In recent years, maritime transportation has played an important role in global economy development. As a result, ship traffic has become more congested. Moreover, ship navigation is susceptible to weather and environmental conditions, and in some cases, it may become dangerous. Therefore, vessels are subjected to high-risk navigation conditions. To understand the latent risk of ship navigation, this study focused on the actual ship behavior. Thus, an analysis of ship behavior was carried out using historical ship navigation based on automatic identification system data. Consequently, a dynamic analysis of the speed and encounter situation was performed. One of the main results of this work was the understanding of the latent risk involved in ships navigating the Seto Inland Sea, which is one of the most congested routes in Japan. Moreover, the risk areas were obtained, and visualized using a geographical information system. The obtained results can be applied to ensure safe navigation and the development of a safe and efficient navigation model.
\end{abstract}

Key words: Maritime traffic, latent risk, ship behavior analysis, AIS (automatic identification system) data, navigation model.

\section{Introduction}

Sea transport is responsible for $90 \%$ of goods and materials transportation in the world [1]. However, ship navigation involves high-risk scenarios as maritime transportation has intensified. In particular, in recent years, with the rapid development of the global economy, ships are increasing in number and size [2]. Consequently, most of the main traffic routes and coastal areas are experiencing congestion. Therefore, ships navigate under risk conditions, and thus maritime accidents have occurred frequently. On the other hand, the characteristic of the ship is the one main reason that makes navigation even more dangerous. Ship navigation is different with respect to the maneuvering of other vehicles. For instance, in cars, brakes can be applied to stop the vehicle when an obstacle is found. Unfortunately, brake systems do not exist for ships. In contrast, ships avoid obstacles by deceleration and veering, using a propeller. Therefore,

Corresponding author: Hidenari Makino, Ph.D., research fields: maritime traffic engineering and maritime sciences. the maneuvers of avoidance and returning to original route are time consuming and in high risk. In addition, they have the negative influence in the efficiency and fuel costs. Navigation with large ships is thus more difficult. Furthermore, ship navigation is sensitive to external forces such as wind and currents, as well as the visibility conditions and traffic situation. Weather conditions can be checked before the voyage. However, it is difficult to reliably predict the traffic situation. For these reasons, many latent risks are present during navigation.

This study focused on the actual ship behavior to understand the characteristic of ship navigation and the maritime traffic situation, especially considering the latent risk in ship navigation. The purpose is to develop a sensible and appropriate traffic model for the safety and efficiency ship navigation.

Related studies to this research have shown that the application of behavior analyses to land transport vehicles is possible [3-5]. Precisely, these studies analyzed the vehicle behavior to understand the driving features of the drivers and the effect of road 
infrastructures. For instance, Yokoyama et al. [6] used recorded data from drivers to analyze the real driving behavior to reduce the number of traffic accidents in the future. In the maritime transport field, most studies on ship behavior analysis have been carried out with simulation models [7-9]. Although these models can describe the dynamic motion of the ship, most of them can be only applied to a few specific ships.

The AIS (automatic identification system) is ship navigation equipment that provides extensive navigational information of ships. Therefore, AIS data has been used in maritime research to understand the actual ship behavior $[10,11]$. These studies have shown that the analysis of historical ship navigation using AIS data is possible so as to unveil the characteristics of real ship movement. These studies were good use of the actual ship navigational data.

In this study, the characteristics of ship behavior were analyzed based on the speed and encounter situation obtained from AIS data. A dynamic analysis based on real ship movement data was carried out in this study, and the latent risks in navigation were extracted. Moreover, the risk areas were analyzed and presented using the GIS (geographic information system) techniques. The results of this study can be applied to develop an appropriate traffic model and help the operators understand the navigational situation before their voyage.

\section{Ship Traffic Based on AIS Data}

\subsection{AIS Data}

So far, the ships navigation features has been analyzed by the varied data. Most of the data analysis has focused on the individual ship. In order to analyze a group of ship and the traffic situation in a wide ocean area, this study used the AIS data. AIS technology automatically provides information about the ship to other ships and coastal authorities, using VHF (very high frequency) radio waves. Indeed, it is possible to obtain navigation information of ships using AIS in an accurate and quantitative manner. This information includes dynamic, static and voyage-related data. The information supplied by AIS data is detailed in Table 1.

There are two classes of shipboard equipment:

- Class A (mainly used by commercial vessels);

- Class B (mainly used by small ships such as fishing vessels and pleasure boats).

Information transmission with Class B equipment is simpler. AIS Class A is compulsively installed aboard all international voyaging ships larger than 300 GT (gross tonnage), all non-international voyaging ships larger than $500 \mathrm{GT}$, and all passenger ships.

\subsection{Investigation of Ship Traffic}

In this study, the research area was Seto Inland Sea (from $134^{\circ} 53^{\prime} 25^{\prime \prime} \mathrm{E}, 34^{\circ} 44^{\prime} 10^{\prime \prime} \mathrm{N}$ to $135^{\circ} 27^{\prime} 52^{\prime \prime} \mathrm{E}$, $34^{\circ} 15^{\prime} 30^{\prime \prime} \mathrm{N}$ ), which is located in the western part of Japan. A map of the research area is shown in Fig. 1. The research period was between March 1st and 7th, 2012. According to the statistics of ship numbers using the MMSI numbers, it was found that the total number of ships traversing the research area was 2,589 in such a research period. There were more than 1,000 ships navigating every day [12]. The Seto Inland Sea route is a primary traffic route in the area for the transportation between Japan and China, and South Korea, it is used by ships navigating between the east and west. The route connects the traffic exits in the Kamon Straits (on the westernmost side of Japan) and the Osaka Bay (in the center of Japan). This area also harbors two main ports, Kobe and Osaka.

Table 1 Contents of AIS data

\begin{tabular}{|l|l|}
\hline Dynamic data & $\begin{array}{l}\text { Ship position, coordinated universal time, SOG (speed over ground), COG (course over ground), heading, } \\
\text { navigational status, etc. }\end{array}$ \\
\hline Static data & $\begin{array}{l}\text { Vessel's MMSI (maritime mobile service identity) number, IMO (International Maritime Organization) } \\
\text { number, ship's name, type of ship, length and breadth, etc. }\end{array}$ \\
\hline Voyage-related data & Draught, destination, estimated time of arrival, etc. \\
\hline
\end{tabular}


Most voyaging ships stop at these ports, therefore, the route is always congestion. In addition, the route has unfavorable geographical conditions such as a narrow channel, scattered islands, and complex tidal currents. These conditions make ship navigation in this area difficult. On the other hand, there is a route crossing the Seto Inland Sea, it is used by ship navigating between the south and north. These crossing routes in the inland sea area were evidenced by analyzing the AIS data on the COG (course over ground) of the ships. The blue and red dots in Fig. 1 indicate the trajectories of ships navigating the east-west route and the south-north route, respectively. The trajectories were obtained from the AIS data regarding the positions of the ships, and presented with the use of GIS. There were a large number of cargos and tankers following the east-west route. These ships transport goods, materials and energy resources, supporting the economy and logistics of the region. Fig. 2 indicates the traffic volume of these routes derived based on the ship voyages. It was obtained by each ship sailing on the return voyage between the routes, using AIS data analysis. In contrast to the number of ships in the east-west route, the number of ships in the south-north

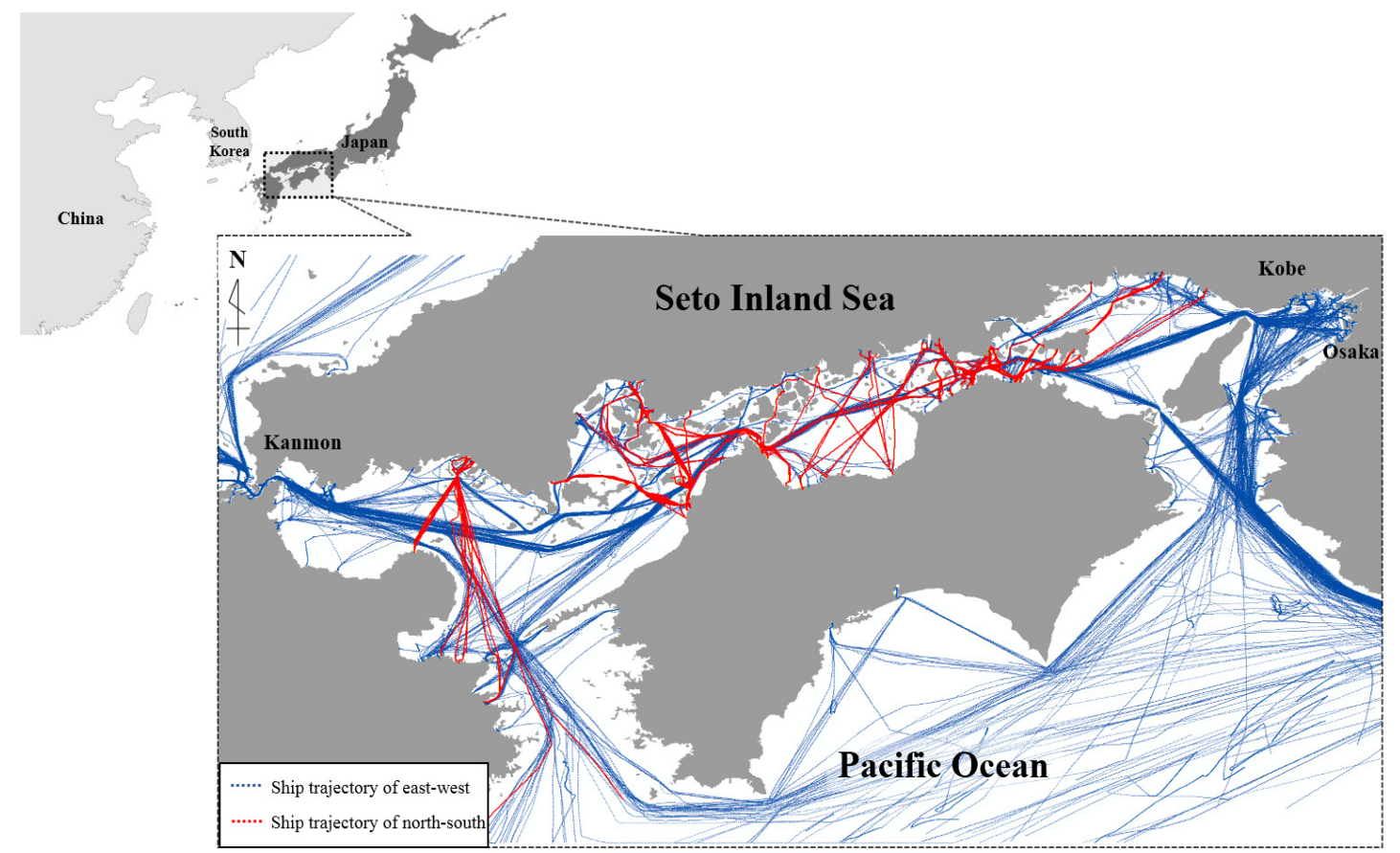

Fig. 1 Research area and ship trajectories.

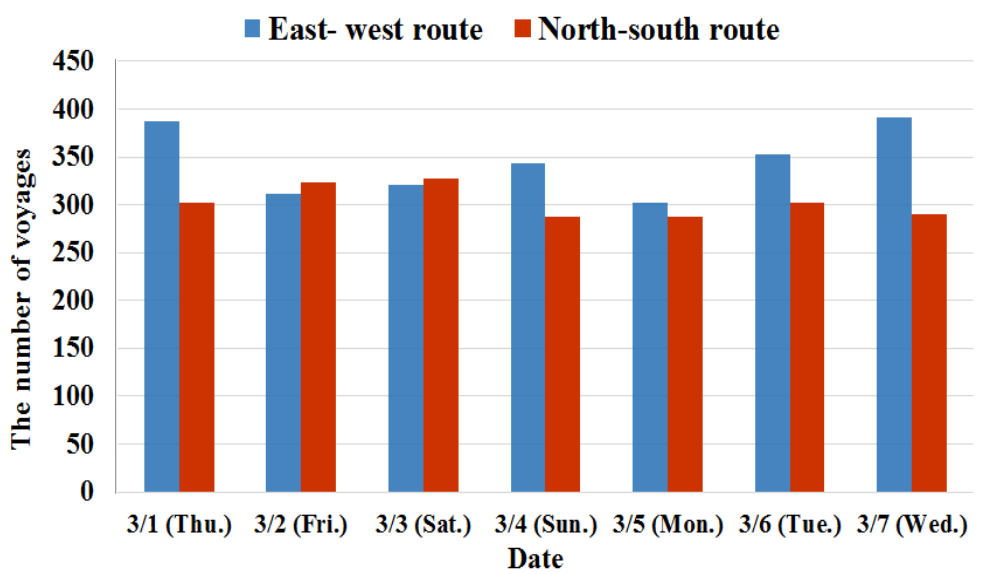

Fig. 2 Traffic volume based on the ship voyages in the east-west route and north-south route. 
route was lower, but the traffic was very busy. Most of these ships were ferries, which frequently sail across the Seto Inland Sea route. These ships are responsible for the local transportation of people moving between the islands. Thus, the number of ships crossing is high, and as a result, the traffic situation is complex, showing the latent risk of navigation in this inland area.

\section{Analysis of Ship Behavior Based on Speed}

In this study, the ship navigation speed was used to analyze the ship behavior. The analysis of speed is a conventional method used to evaluate safety and economic aspects of ship navigation [13].

The position and destination of vessels transiting the east-west route, without stopping at any port, were extracted. Using their MMSI numbers, it was possible to identify 106 ships passing across the inland sea during the research campaign. The authors examined the case of a ferry ship, and used this as case study to make a qualitative analysis of the results, and thus to understand the characteristics of the ships navigating the inland sea. A dynamic analysis approach was followed, which involved tracking the position and navigational situation of this ship across different time series. In this way, it is possible to understand the behavior of the ship in a detailed and accurate manner.

The total length of the ferry ship was $160 \mathrm{~m}$, and the sea speed (i.e., the maximum speed when the ship is sailing with cargo) was 22.9 kns. During the research period, this ship sailed the inland sea route six times, departing at 17:00 and arriving at 5:30 the next day, and cruising between the Moji and Osaka Ports every day. In this work, it was discussed three cruising cases from Moji to Osaka. According to the data provided by the Japan Meteorological Agency, during the investigation period, the weather conditions were zero visibility, low rainfall and low wind speed. Therefore, wind had less influence on the navigation speed.

The research area was divided into seven zones, accounting for the straits in the Seto Inland Sea, to compare the characteristics of the ship behavior in each area and identify their changes throughout the inland sea. The defined zones are shown in Fig. 3. The Kurushima Strait, Bisan Seto and Akashi Strait correspond to Zones 2, 4 and 6, respectively. The red dots in the Fig. 3 show the trajectories of the ship in these three cases. During the voyages, it took approximately $12.5 \mathrm{~h}$ to complete 245 nautical miles.

Figs. 4-6 show the time series of the changes in the ship speed for Cruisings 1, 2 and 3, respectively. The zones in which this ship navigated each strait is indicated with blue strips in Figs. 4-6. The traveling time and the speed according to each zones are listed in Table 2.

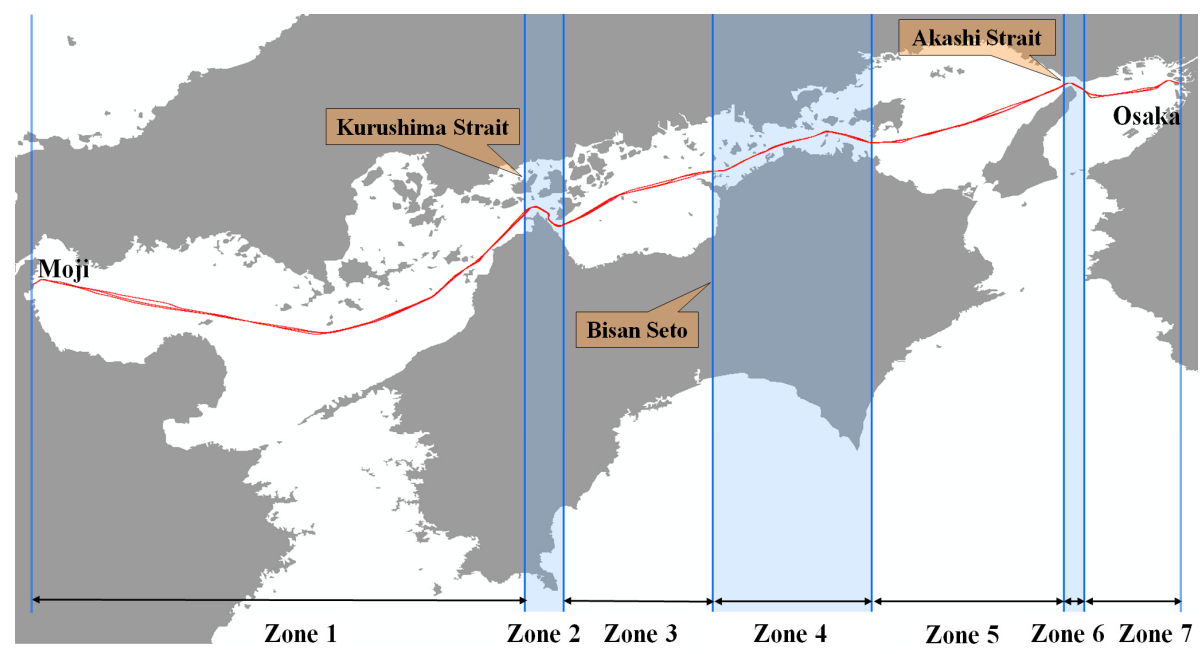

Fig. 3 Zone areas and trajectories of the ferry ship. 


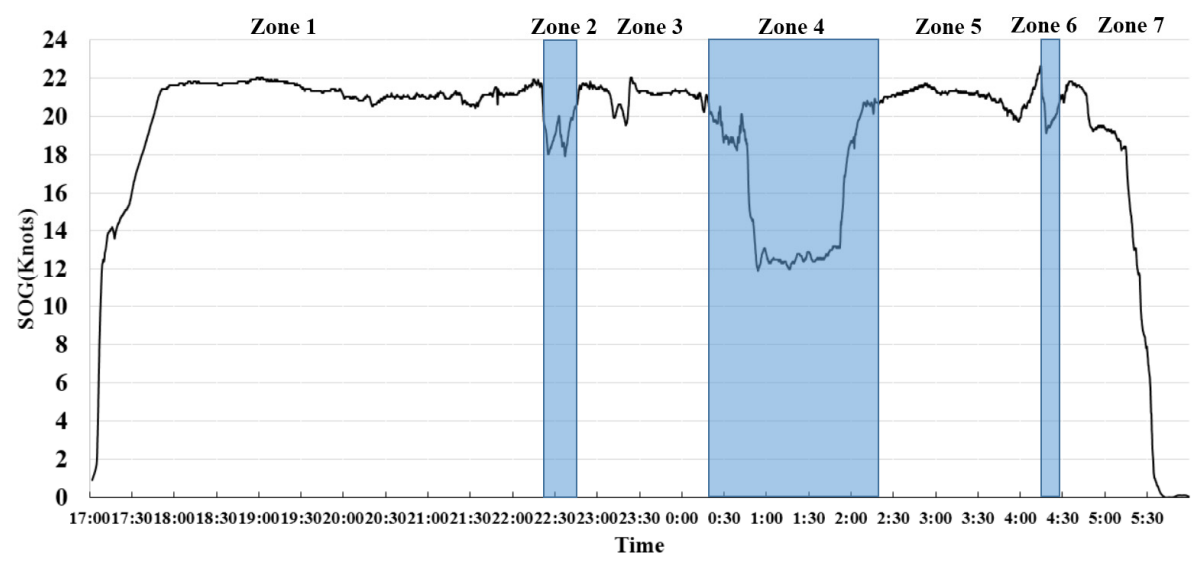

Fig. 4 Speed of Cruising 1 in the Seto Inland Sea route.

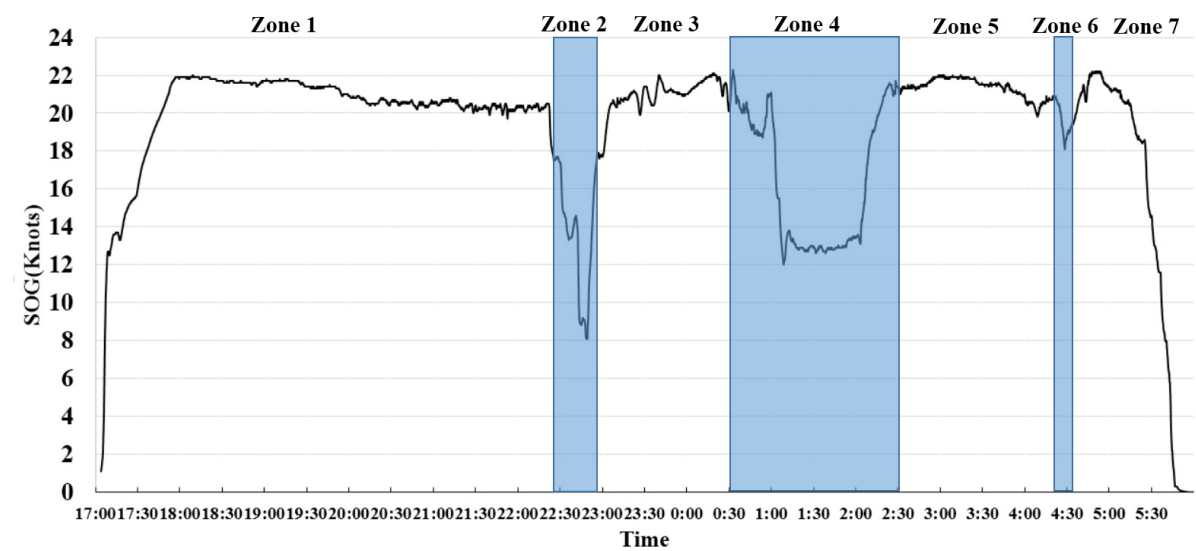

Fig. 5 Speed of Cruising 2 in the Seto Inland Sea route.

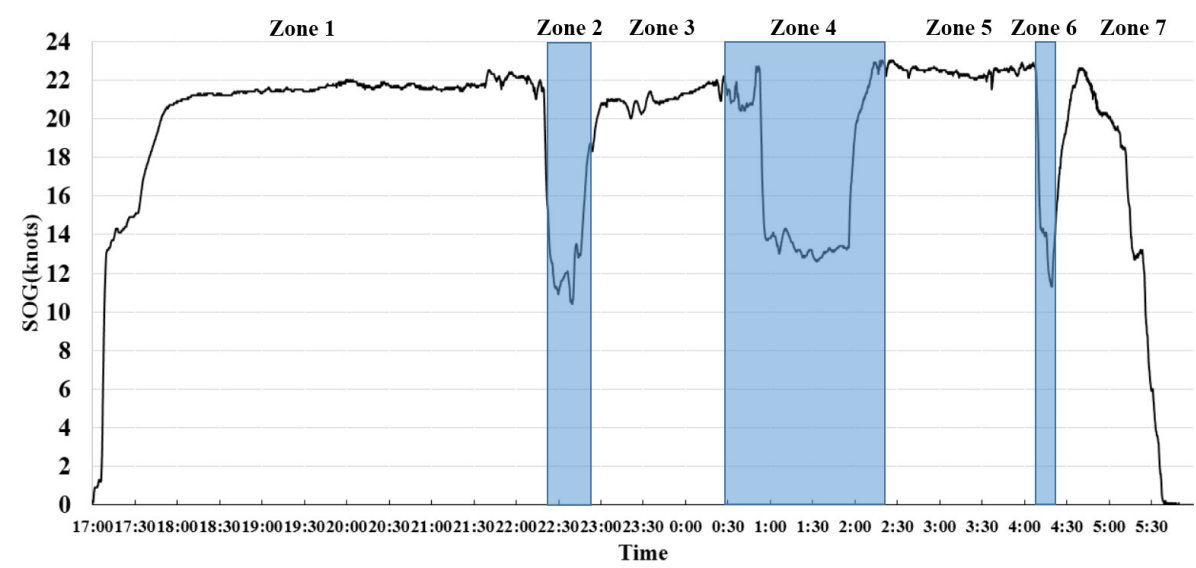

Fig. 6 Speed of Cruising 3 in the Seto Inland Sea route.

From the speed distributions and the analysis results in Table 2, it was found that most of the ship was approximately $20 \mathrm{kns}$, although in some zones such as Zones 1, 2 and 3, the speed reached up to $22.9 \mathrm{kns}$ (sea speed of the ship) at some instants. Moreover, the change in speed was frequently checked ${ }_{2}$ as shown in Zones 2, 4, and 6. According to the information of tidal currents, in the Kurushima Strait (Zone 2), it was north when the ship navigated during Cruisings 1, 2 and 3 . The slackest current was between 1 and 2 kns during Cruising 1, and the strongest one was over 4 kns during Cruising 2. Thus, the speed decreased due to the upstream current. The tidal current in the Akashi Strait (Zone 6) was the slackest during Cruising 3, 
Table 2 Cruising time and speed for Cases 1, 2 and 3.

\begin{tabular}{|c|c|c|c|c|c|c|c|c|}
\hline \multicolumn{2}{|l|}{ Item } & Zone 1 & Zone 2 & Zone 3 & Zone 4 & Zone 5 & Zone 6 & Zone 7 \\
\hline \multirow{5}{*}{ Cruising 1} & Navigational time & 17:00 22:11 & $22: 11 \sim 22: 47$ & $22: 47 \sim 00: 17$ & 00:17 02:19 & 02:19 04:13 & $04: 13 \sim 04: 25$ & 04:25 05:36 \\
\hline & $\begin{array}{l}\text { Traveling hour } \\
\text { (hours, minutes) }\end{array}$ & $5 \mathrm{~h} 11 \mathrm{~min}$ & $36 \mathrm{~min}$ & $1 \mathrm{~h} 30 \mathrm{~min}$ & $2 \mathrm{~h} 2 \mathrm{~min}$ & $1 \mathrm{~h} 54 \mathrm{~min}$ & $12 \mathrm{~min}$ & $1 \mathrm{~h} 11 \mathrm{~min}$ \\
\hline & Max. speed (kns) & 22.0 & 21.9 & 22.0 & 21.1 & 22.2 & 22.6 & 21.8 \\
\hline & Mean of speed (knots) & 20.7 & 19.5 & 21.1 & 16.5 & 21.0 & 20.3 & 19.4 \\
\hline & $\begin{array}{l}\text { SD (standard deviation) } \\
\text { of speed }\end{array}$ & 1.52 & 0.61 & 0.47 & 2.97 & 0.42 & 0.95 & 3.78 \\
\hline \multirow{5}{*}{ Cruising 2} & Navigational time & $17: 00 \sim 22: 27$ & 22:27 23:02 & 23:02 00:32 & 00:32 02:31 & 02:31 04:23 & 04:23 04:36 & 04:36 05:46 \\
\hline & \begin{tabular}{|l}
$\begin{array}{l}\text { Traveling hour } \\
\text { (hours, minutes) }\end{array}$ \\
\end{tabular} & $5 \mathrm{~h} 26 \mathrm{~min}$ & $36 \min$ & $1 \mathrm{~h} 30 \mathrm{~min}$ & $1 \mathrm{~h} 59 \mathrm{~min}$ & $1 \mathrm{~h} 52 \mathrm{~min}$ & $13 \mathrm{~min}$ & $1 \mathrm{~h} 10 \mathrm{~min}$ \\
\hline & Max. speed (kns) & 22.0 & 20.5 & 22.1 & 22.3 & 22.0 & 20.6 & 22.2 \\
\hline & Mean of speed (knots) & 20.5 & 14.8 & 21.1 & 17.1 & 21.3 & 19.3 & 20.1 \\
\hline & $\begin{array}{l}\text { SD (standard deviation) } \\
\text { of speed }\end{array}$ & 1.81 & 3.26 & 0.53 & 2.71 & 0.49 & 0.39 & 3.51 \\
\hline \multirow{5}{*}{ Cruising 3} & Navigational time & $17: 00 \sim 22: 20$ & 22:20 22:56 & $22: 56 \sim 00: 27$ & $00: 27 \sim 02: 21$ & 02:21 04:08 & 04:08 04:26 & 04:26 05:36 \\
\hline & $\begin{array}{l}\text { Traveling hour } \\
\text { (hours, minutes) }\end{array}$ & $5 \mathrm{~h} 20 \mathrm{~min}$ & $36 \mathrm{~min}$ & $1 \mathrm{~h} 31 \mathrm{~min}$ & $1 \mathrm{~h} 54 \mathrm{~min}$ & $1 \mathrm{~h} 47 \mathrm{~min}$ & $18 \mathrm{~min}$ & $1 \mathrm{~h} 10 \mathrm{~min}$ \\
\hline & Max. speed (kns) & 20.9 & 15.5 & 21.0 & 17.8 & 22.4 & 14.9 & 19.1 \\
\hline & Mean of speed (knots) & 22.5 & 22.0 & 22.0 & 23.0 & 23 & 22.5 & 22.6 \\
\hline & $\begin{array}{l}\text { SD (standard deviation) } \\
\text { of speed }\end{array}$ & 2.68 & 3.11 & 0.43 & 2.19 & 0.22 & 2.12 & 2.95 \\
\hline
\end{tabular}

but the speed rapidly decreased when passing across this strait. This is considered to be the other influencing factor on the speed. The ship decelerated when crossing Zone 4, mainly due to the Bisan Seto route speed restrictions that does not allow navigating at speeds greater than $12 \mathrm{kns}$. The navigational time and traveling schedule were recorded when the ship crossed the lines of each zone. The collected data was used to obtain the maximum, mean and SD of speed, and are used to observe the navigation situation of the ship in every voyage. In these cases, an average speed of $19.6 \mathrm{kns}$ was used to calculate the SD speed in every zone areas, which obtained from the navigational distance and time. The SD is a measure of the variability in the speed of the ship, and it is particularly prominent when crossing the straits. Due to the type of service this ship provides, she must sail regularly to arrive the destination on time in spite of the weather conditions and traffic situation every day. It can be seen that the traveling times were similar in each cruising.

The latent risks of the ship navigation by the analysis of speed and travel time are summarized as follows:

- The ship is changed frequently and slowed down when passing through both straits. It must be remarked that there is a large influence of the currents and route restrictions as well. However, the behavior was not good to the navigation safety and efficiency;

- The ship was able to rapidly increase the speed after a slowdown, in order to catch the destination on time. Moreover, the navigation speed was decreased close to $12 \mathrm{kns}$ in restricted route, never less than this speed.

However, these conditions along with traffic congestion may lead to maritime accidents. For this reason, these are considered as high-risk conditions.

\section{Risk Analysis Based on Encounter Situation}

\subsection{Analysis of Encountering Ships and Approaching Distance}

To understand in detail the reasons for ship deceleration and the subjacent latent risk during navigation, the authors analyzed the encounter 
situation and the approaching distance between the ships. The AIS data transmission interval depends on the navigational status. Therefore, the transmitted data is irregular such as the speed of the ship. The position was interpolated at a rate of one second to calculate the distance between ships. According to the dynamic calculation and analysis, the navigation situation was understood on the basis of the closest distance and the encounter situation with an approaching ship. These factors are often used to evaluate the collision risk [14]. Generally, a sailing ship performs an evading action when a target ship within two nautical miles ahead is detected. Thus, if a ship enters the domain of one nautical mile, there is a high risk of collision. In this work, the authors developed a program that counts the number of ships approaching within a radius of one nautical mile and the distance between these ships.

The types of encounter situations were based on the Prevention of Collision at Sea Act (1972), which specifies three types according to the angle between the two ships. These ship encounter situations are illustrated in Fig. 7. The analysis results of encounter situation in the cases are indicated in Table 3.

The number of ships in overtaking and head-on positions were larger than those in crossing positions. Since the inland sea is narrow and the speed of ferry ships is greater than that of any other types of ships, the authors focused on discussing the encounter situation of crossing.

\subsection{Risk Areas}

The results obtained from the analysis were used to evaluate the navigation risk, and GIS techniques were used for this purpose. The applied method was the analysis of the density distribution of risk using a KDE (kernel density estimation) approach, which is one of the most popular methods for analyzing the properties of a partial point event distribution [15], as it is simple to understand and implement. The point event in the analysis used risk labels related to the encounter situation and approaching distance. The catalog of risk labels are listed in Table 4, with $n$ taken as the number of ships in a given situation. Crossings were considered as high-risk situations and the risk label depended on the approaching distance, being the most dangerous situation when entering within 0.5 nautical miles.

Figs. 8-10 show the distribution of ship navigation risks. High and low densities are colored in red and yellow, respectively. From the results, it is possible to determine the risk areas for each zone, in particular for Zones 1, 3 and 4. As explained above, the ship experiences different traveling times across Zone 1. The risk distribution demonstrates this ship sailed Zone 1 in a complex traffic situation, and thus the risk of collision was high. As the strength and direction of

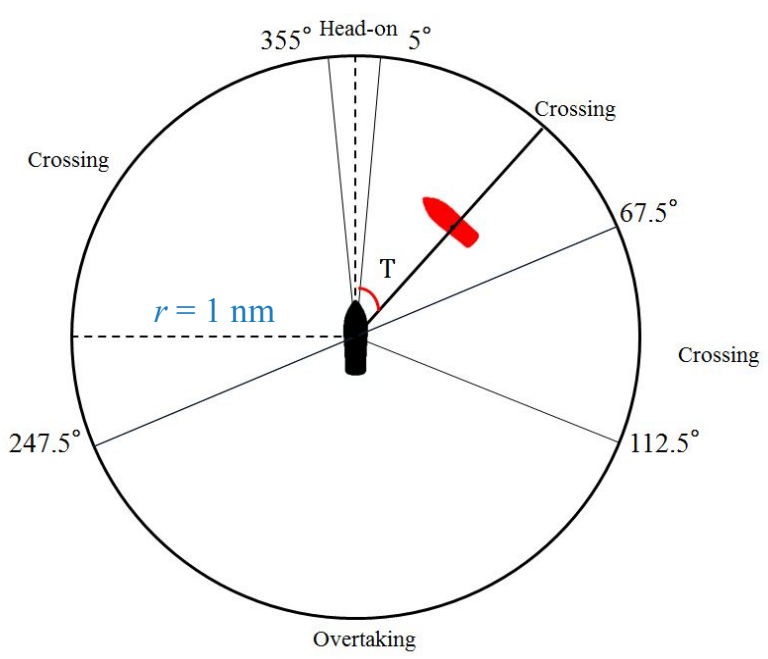

Fig. 7 Ship domain and encounter situation.

Table 3 The encounter situation of Cruisings 1, 2, and 3.

\begin{tabular}{|c|c|c|c|}
\hline \multirow{2}{*}{ Study cases } & Overtaking & Head-on & Crossing \\
\hline & \multicolumn{3}{|c|}{ (The number of ships) } \\
\hline Cruising 1 & 39 & 73 & 7 \\
\hline Cruising 2 & 43 & 62 & 13 \\
\hline Cruising 3 & 34 & 77 & 5 \\
\hline
\end{tabular}

Table 4 Risk labels depending on the encounter situation.

\begin{tabular}{llll}
\hline \multirow{2}{*}{ Risk label } & \multicolumn{3}{c}{ Encounter situation } \\
\cline { 2 - 4 } & Overtaking & Head-on & Crossing \\
\hline$d>0.5$ n.m. and & $n \times 1$ & $n \times 1$ & $n \times 5$ \\
$d<1$ n.m. & $n \times 1$ & $n \times 1$ & $n \times 10$ \\
$d<0.5$ n.m. & $n \times 1$ & \\
\hline
\end{tabular}




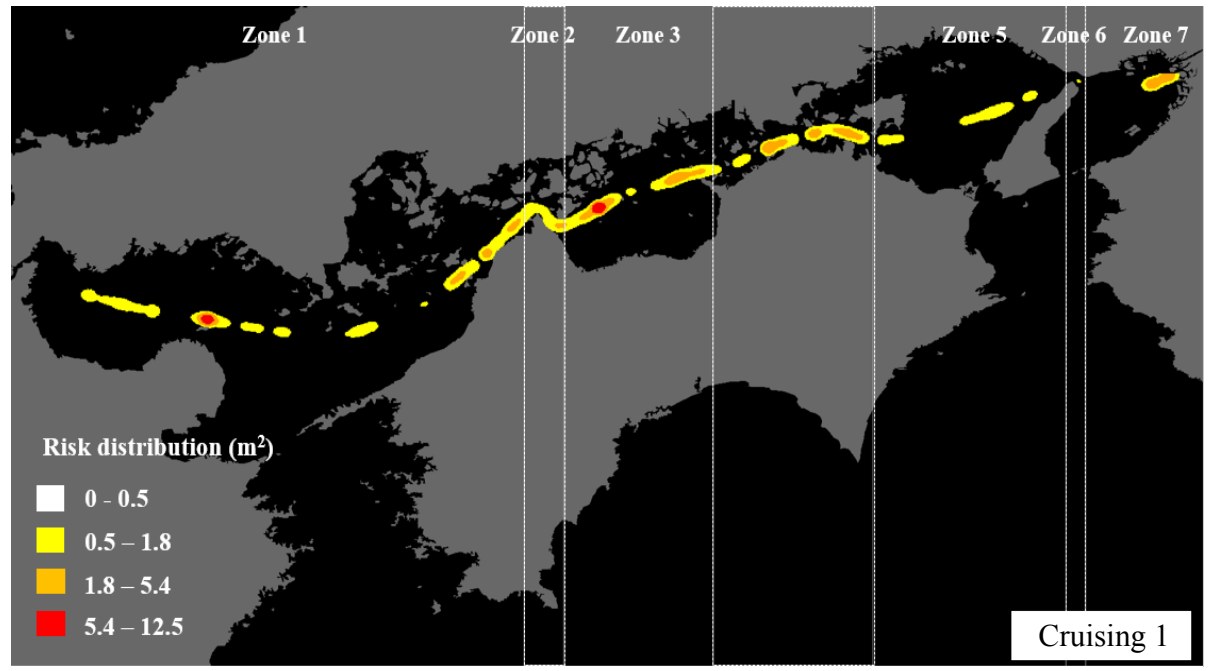

Fig. 8 Risk distributions of Cruising 1 in Seto Inland Sea.

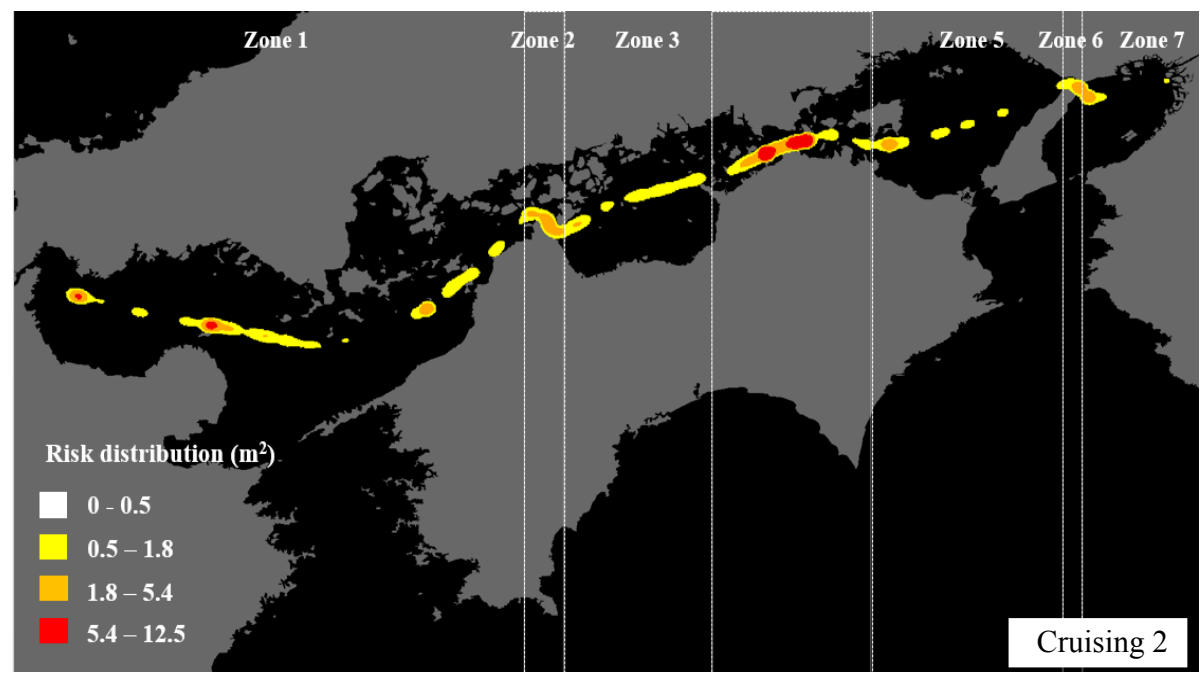

Fig. 9 Risk distributions of Cruising 2 in Seto Inland Sea.

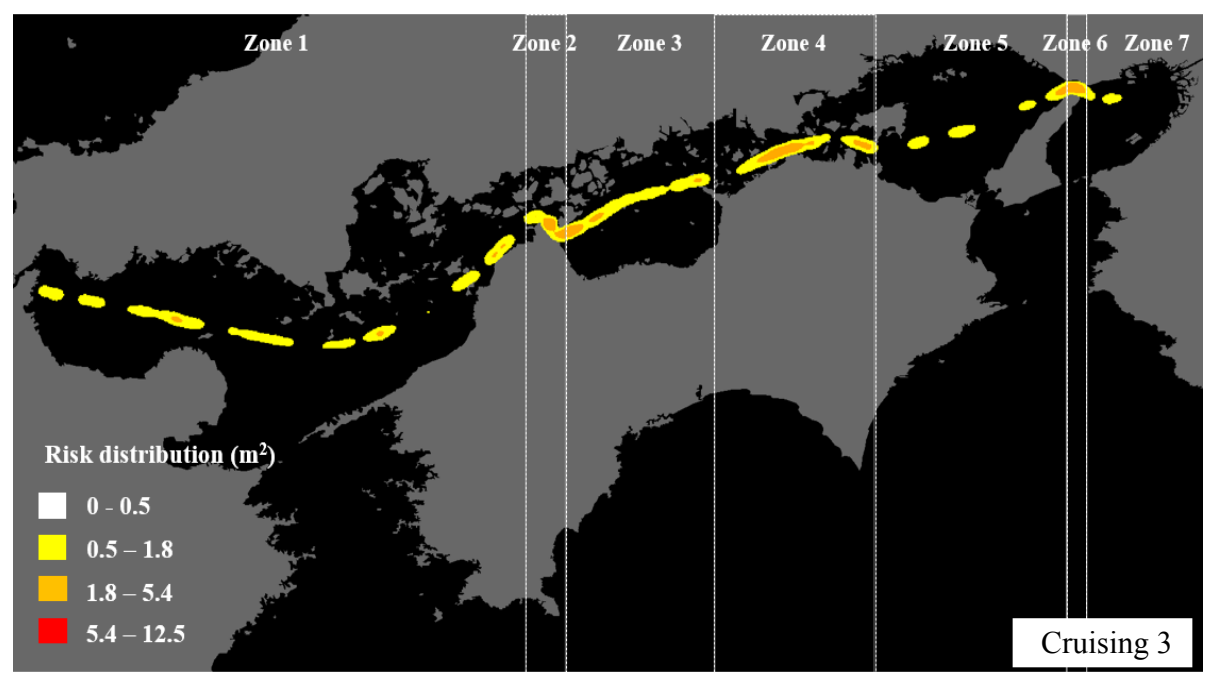

Fig. 10 Risk distributions of Cruising 3 in Seto Inland Sea. 
currents change with time in the Kurushima Strait, the route demands a rare and unique rule. To fit the current and meet the rules of the route, many ships change their course before entering the route. Therefore, a high-risk area in Zone 3 is present due to a sudden change in the course of the other ships, leading to multiple ship crossings. Zone 4 corresponds to Besen Seto. In this zone, a large number of ship crossings take place. This zone should be carefully sailed. Finally, the results from this analysis can be used to avoid collision accidents.

\section{Discussion}

This study presents a method for the analysis of actual ship navigation. Moreover, a dynamic analysis was performed to understand the real behavior of ships in detail. Therefore, it can be considered as an innovative study in the sense that provides insights into ship traffic and unveils the latent risk in ship navigation. Although the results presented in the paper are for a particular ferry ship, the analysis can be applied to any regular ship to better understand the traffic situation within the research area. Future work will be devoted to the analysis of the navigational behavior of the other types of ships. Certainly, a quantitative and detail analysis of the actual ships behavior will result in a sensible and appropriate simulation traffic model for the safety and efficiency of ship navigation.

\section{Conclusions}

This paper presents an analysis on ship behavior using the real ship movement from AIS data. According to the analysis, ship behavior can be understood following a dynamic analysis. The main results are the following:

Traffic volume through the north-south and east-west routes was obtained. It was observed that a larger number of ships crossing the main route (east-west routes). The traffic situation is complex, showing the latent risk of navigation in this sea area.

Changes in the speed were frequent but diminished when the ship passed through both straits, and the ship rapidly increased the speed after a slowdown. Thus, these are considered as high-risk conditions.

The encounter situation and approaching distance of ships navigating the entire voyage was described. The results obtained from the analysis provided the risk areas.

\section{Acknowledgment}

The research was financially supported by the Sasakawa Scientific Research Grant from the Japan Science Society. Research number is $28-707$.

\section{References}

[1] Dolivo, R. 2007. "The IBM Secure Trade Lane Solution." ERCIM (European Research Consortium for Informatics and Mathematics) News 68: 45-47.

[2] WSC (World Shipping Council). 2015. Some Observations on Port Congestion, Vessel Size and Vessel Sharing Agreements. Washington, D.C.: WSC.

[3] Higgs, B., and Abbas, M. 2013. "A Two-Step Segmentation Algorithm for Behavioral Clustering of Naturalistic Driving Styles." In Proceedings of IEEE 16th Conference on Intelligent Transportation Systems (ITSC), 857-62.

[4] Dang, R. N., Zhang, F., Wang, J. Q., Yi, S. C., and Li, K. Q. 2013. "Analysis of Chinese Driver's Lane Change Characteristic Based on Real Vehicle Tests in Highway." In Proceedings of IEEE 16th Conference on Intelligent Transportation Systems (ITSC), 1917-22.

[5] Nakamura, T., Nakayama, T., Uno, N., and Yamamura, K. 2016. "A Vehicle Behavioral Analysis of the Signal Pre-warning Information Provided to the Driver." Journal of Traffic and Transportation Engineering 4 (1): 11-7.

[6] Yokoyama, D., and Toyoda, M. 2015. "A Large Scale Examination of Vehicle Recorder Data to Understand Relationship between Drivers' Behaviors and Their Past Driving Histories." In Proceedings of 2015 IEEE International Conference on Big Data, 2877-9.

[7] Goerlandt, F., and Kujala, P. 2011. "Traffic Simulation Based Ship Collision Probability Modeling." Reliability Engineering \& System Safety 96 (1): 91-107.

[8] Montewka, J., Hinz, T., Kujala, P., and Matusiak, J. 2010. "Probability Modelling of Vessel Collisions." Reliability 
Engineering \& System Safety 95 (5): 573-89.

[9] Statheros, T., Howells, G., and McDonald-Maier, K. 2008. "Autonomous Ship Collision Avoidance Navigation Concepts, Technologies and Techniques." Journal of Navigation 61 (1): 129-42.

[10] Gao, X., Makino, H., and Furusho, M. 2015. "Analysis of Actual Situation of Waiting Ship Using AIS Data." In Proceedings of the 25th International Ocean and Polar Engineering Conference, 883-8.

[11] Makino, H. 2013. "Verification of the Time Tsunami Attacked Coasting Ships Using AIS - Case of the 2011 East Japan Tsunami." Journal of Earth Science and Engineering 2: 125-9.

[12] Gao, X., Makino, H., and Furusho, M. 2015. "Research on the Real Movement of Container Ship between Japan, China, and South Korea using AIS data." In Proceedings of 11th International Conference on Marine Navigation and Safety of Sea Transportation, 135-41.

[13] Yamada, K., Arimura, N., and Tanaka, K. 1985. "The Travelling-Time Distribution of Vessels for Evaluation of Maritime Traffic (1)." National Maritime Research Institute 22 (4): 311-7.

[14] Colley, B. A., Curtis, R. G., and Stockel, C. T. 1984. “A Maritime Traffic Flow and Collision Avoidance Computer Simulation." Journal of Navigation 37 (2): 232-50.

[15] Bailey, T. C., and Gatrell, A. C. 1995. Interactive Spatial Data Analysis. Essex: Longman. 